\title{
Drivers, impacts, mechanisms and adaptation in insect invasions
}

\author{
Matthew P. Hill · Susana Clusella-Trullas • \\ John S. Terblanche • David M. Richardson
}

Received: 3 December 2015/ Accepted: 14 January 2016/Published online: 26 February 2016

(C) Springer International Publishing Switzerland 2016

\section{Introduction}

Charles Darwin and other researchers in the nineteenth century made important contributions to the knowledge of invasive species. It is, however, only in the last half century, and especially over the last three decades, that researchers have attempted to collate theories and concepts to forge a predictive understanding of the processes that mediate invasiveness of introduced species, and invasibility of recipient ecosystems (Richardson 2011a). Invasion ecology has subsequently grown to become one of the most vibrant sub-disciplines of ecology. Biological aspects were the focus in early studies of biological invasions. More recently, as invasive species have become more widespread and their impacts on biodiversity, ecosystem functioning and human health have increased, more attention is being given to the many human dimensions of invasions

Guest editors: Matthew P. Hill, Susana Clusella-Trullas, John S. Terblanche \& David M. Richardson / Insect Invasions

M. P. Hill $(\bowtie) \cdot$ J. S. Terblanche

Department of Conservation Ecology and Entomology, Centre for Invasion Biology, Stellenbosch University, Private Bag X1, Matieland 7602, South Africa e-mail: matthill@protonmail.com

S. Clusella-Trullas · D. M. Richardson Department of Botany and Zoology, Centre for Invasion Biology, Stellenbosch University,

Private Bag X1, Matieland 7602, South Africa and to ways of slowing or preventing new invasions and mitigating the negative effects of current invasions (Richardson 2011b). Although there are interesting and important invasive species from all taxonomic groups, certain groups have been studied more systematically than others, at least as reflected in the invasion literature (Pyšek et al. 2008). For example, plants have been disproportionally well studied, and many of the most prominent hypotheses and theories in invasion ecology were derived from studies of plants (Pyšek et al. 2006; Catford et al. 2009). Although many "poster child" examples of animal invasions have been well explored, the total number of detailed studies of invasive animals and the overall understanding of invasions in many animal groups has lagged behind that of plants. This is also true for insects; although they are the most diverse class of animals, invasive insect species are underrepresented in the literature on such aspects as the ecological impacts of invasions (Kenis et al. 2009).

In tracing the history of study of invasive insects, it is not surprising that much of the early work focussed on species of agricultural and economic importance (Pyšek et al. 2008; Kenis et al. 2009; Sutherst 2014). Many invasive pest species of insects have thus received considerable research attention, although not always in the context of what is now considered "invasion science". The Hessian fly, Mayetiola destructor, a pest of cereal crops, provides a clear example of how components of what is now known as invasion science came together in ca. 1780, long before the formalisation of the discipline of ecology. Pauly (2002) describes how 
knowledge of horticultural introductions as a pathway, insect identifications and life history, and the structuring of policy were considered when tackling this pest species at the end of the eighteenth century. In the 1930s increased attention was given to predicting outbreaks and abundances of different pest insect species. This coincided with the increasing availability of climate records to draw simple relationships between pest distributions and climatic factors (notably precipitation and temperature) (Cook 1929). Inevitably, this led ecologists to pose questions about predicting where introduced insects may establish in new geographical regions (Cook 1931).

Ideas such as those mentioned above received more attention over the ensuing decades and Charles Elton, in his famous 1958 book, cited many insect examples in outlining various components in the first treatise on what would come to be called invasion ecology (Elton 1958). Of the 195 organisms identified to at least genus level in the index to Elton's (1958) book, 87 (45\%) are insects. Amongst the insights regarding ecological impacts of invasive species and the dynamic nature of future and continued invasions, there are important messages from Elton's book regarding invasive insects. One regards the pathways for insect invasions: "Nearly all the insect immigrants I have been discussing were introduced by mistake, and often in spite of heavy screens of quarantine" (p. 73). The pathways that facilitate insect invasions have changed radically since Elton's assessment, but accidental introductions remain the dominant drivers of insect invasions (Roderick and Navajas 2015). Many invasive insects arrived as hitchhikers on plant material (including live plants and cut flowers); this is the most important pathway for European interceptions (Kenis et al. 2007) and is a major pathway for forest pests in the USA (Liebhold et al. 2016). Much research has focussed on quantifying the importance of different pathways and exploring the implications for biosecurity. Increasing volumes of global trade have led to calls for efficient solutions to transporting goods which has presented new challenges for intercepting insect invasions. For instance, the increase in the use of wooden crates and pallets in the 1980s facilitated the transport of various wood-boring beetles into the USA, notably Agrilus planipennis, the emerald ash borer (Herms and McCullough 2014). Besides changes to traditional pathways of insect invasions, new pathways have also emerged. For example, the huge increase in the volume of passenger travel on aircraft has allowed for many more insects to hitchhike in luggage (Liebhold et al. 2006). Also, the internet has facilitated the global dispersal of many insects through regular postal services-as pets, for pet food, entomophagy and many other purposes. This pathway is largely unregulated, and screening facilities in most countries are poorly equipped to deal with biosecurity issues associated with this burgeoning area of trade.

Another striking insight that emerges from Elton's (1958) book is that many of the insect taxa that he used as examples in his book are major invasive species now, but were already well established as invasive species then, some for several decades before the 1950s. These include the poster-children of invasion biology at that time: the Argentine ant, Linepithema humile (first recorded in Florida in 1891), the gypsy moth, Lymantria dispar (escaped captivity in the USA, ca. 1869) and the big-headed ant, Pheidole megacephala (already widespread in the $1800 \mathrm{~s}$ ). All three of these species are still very important invasive species and are listed among " 100 of the world's worst invasive alien species" (Lowe et al. 2004). Additional examples of invasive agricultural pests highlighted by Elton (1958), including the Mediterranean fruit fly, Ceratitis capitata, the codling moth, Cydia pomonella and the Colorado potato beetle, Leptinotarsa decemlineata, also continue to challenge global food security more than 150 years after they were first reported as being invasive. Thus, the questions surrounding the ecological impacts of invasive species on biodiversity, the economic losses and food security issues posed to agricultural management of pests, and the spread of human diseases via insect vectors remain key focus areas of research. Given the increasing number of insect invaders globally (Huang et al. 2011) and the addition of new global environmental issues including climate change and the rapid transformation of habitats, the challenges associated with prevention, eradication and novel management of insect invasions are increasing in scope and complexity. Advances in technologies to target these aspects of invasion biology include the development of statistical models for predicting distributions (e.g. ecological niche models), next-generation sequencing and marker technologies (e.g. single nucleotide polymorphisms), and the use of online databases to facilitate citizen interest and the rapid collation of new records. Practical methods for detecting low-density 
populations using different trapping methods (e.g. pheromone traps for the gypsy moth) have also been developed since the 1950s. Such tools have contributed to a radical improvement in early detections and the understanding of spread dynamics for important species, and have facilitated management strategies to slow overall spread (Sharov et al. 2002), through to eradication (Suckling et al. 2014).

Although insects have contributed significantly to the understanding of some key issues in invasion ecology (Roderick and Navajas 2015), papers dealing with insects made up only $18 \%$ of peer-reviewed outputs in invasion ecology over the period 1980-2006 (Pyšek et al. 2008), and these have strong geographic and taxonomic biases. Most detailed studies of invasive insects have been done in the northern hemisphere, on a relatively small number of taxa. Invasive social hymenoptera taxa have been relatively well studied, especially the honey-bee Apis mellifera and the ants L. humile and Solenopsis invicta (fire ant) (Kenis et al. 2009)—-the first-mentioned being the second most studied invasive organism overall (Pyšek et al. 2008). Most of the other well-studied invasive insect species are pests of agriculture and forestry, or vectors of human disease (Roll et al. 2007). This means that within such a diverse group as invasive insects there is a lack of research attention for many, if not the majority, of species. There is clearly an urgent need to expand the scope of work on insect invasions to improve our understanding of many facets of their invasion ecology.

To address some of the key research priorities on insect invasions, an international workshop on the "Drivers, mechanisms, impacts and adaptation in insect invasions" was held in Stellenbosch, South Africa in November 2014. Deliberations at the workshop focussed on the four main themes listed in the workshop title. The specific aims were:

- to synthesise general understanding of invasive insects by investigating agricultural pests, biological control agents, vectors of human disease and threats to ecosystem functioning;

- to compare and test established hypotheses from invasion biology using invasive insects;

- to uncover knowledge shortfalls in this field and determine key future research directions;

- to foster collaborations to facilitate knowledge transfer, from research through to management.
This paper serves as an introduction to this special issue of Biological Invasions, in which summaries of studies initiated at the workshop have been published, and seeks to provide the context for the selection of papers that are included.

\section{Research on invasive insects}

To synthesise the general understanding of invasive insects and the contributions and knowledge that has been gained from studying insect invasions, we briefly consider a selection of five different 'realms' or research focus areas. These include the different aspects of the primary industries of both agriculture and forestry, the ecological impact of invasive species in natural ecosystems, vectors of human diseases, and the intentional release of species, e.g. for biological control.

\section{Agricultural pests}

The field of invasion biology owes much to the early work of researchers interested in predicting the seasonal abundance and distributions of pest species of agricultural crops. Understanding insect invasions requires species to be adequately described and delineated, which focuses efforts to help border detection (Saccaggi et al. 2016) and management. A striking example of this is the silverleaf whitefly, Bemisia tabaci, which was often considered a single species and was managed accordingly. However, recent genetic analyses have shown "B. tabaci" to comprise many morphologically cryptic species (De Barro et al. 2011; Boykin et al. 2012), a finding that has important implications for management strategies in many regions. The science of predicting distributions and abundances of organisms grew largely from investigations of invasive and pest insects (see Sutherst 2014). In particular, Ceratitis capitata has been the focus of multiple studies that have attempted to describe its broad niche, including bioclimatic zonation (Gjullin 1931), ecological niche models (De Meyer et al. 2008), semi-mechanistic models (Vera et al. 2002) and process-based distribution models (Gutierrez and Ponti 2011). The information generated from modelling the distribution of pest and invasive insect species has driven criticism of approaches and 
benefitted the goals of predictive modelling for ecology overall (Sutherst 2014). Finally, some of the invasion hypotheses developed for plants are also supported for invasive insects of agricultural importance. For example, the glassy winged sharpshooter, Homalodisca coagulata, uses novel weapons in parts of its invaded range. Predators such as spiders are lethally intoxicated when preying on $H$. coagulata in the invaded range, and this has not been observed in the native range (Suttle and Hoddle 2006).

\section{Forest pests}

Substantial advances have been made towards understanding pathways of introduction and the population dynamics and spread of insect invasions through research on a small number of insect pests of native forests and planted forests in North America. Survey data by forest entomologists in Canada and the USA have detected invasions as they have occurred, thereby providing key insights on the processes that drive invasions. In this regard, three poster-child examples have been intensively researched: the hemlock woolly adelgid, Adelges tsugae, the gypsy moth Lymantria dispar, and the emerald ash borer, Agrilus planipennis. These three species have had major ecological and economic consequences. The hemlock woolly adelgid causes widespread mortality of keystone tree species resulting in substantial ecosystem-level changes (Orwig et al. 2012). Gypsy moths can also cause partial or total defoliation of canopies during outbreaks which often results in growth loss and severe physiological stress in trees (Davidson et al. 1999). Research on gypsy moth has elucidated the determinants of time lags and spread patterns, and the importance of long-distance dispersal in invasions (e.g. Johnson et al. 2006; Liebhold and Tobin 2006). Considerable success has been achieved in containing the spread of gypsy moth using inexpensive pheromone-baited traps to detect low-density populations and subsequent spraying programmes. Research on this species has increased our understanding of Allee effects and their roles in invasion, through coupled processes such as lag-phases. Such insights have also revealed opportunities for management (Tobin et al. 2011). The emerald ash borer is a relatively new problem, highlighting the importance of novel pathways for introducing new invasive insects. It was first discovered in North America in 2002 (probably one or two decades after its arrival), by which time it had already spread over large areas. Long-distance dispersal of this species occurs predominantly through the movement of infested firewood or nursery stock (Herms and McCullough 2014).

\section{Human disease vectors}

The major focus on invasive insect zoonotic vectors (either vectoring human or animal diseases) has been on mosquitoes in general, and, in particular, the genus Aedes which has been well studied because of its broad suite of transmissible diseases, including dengue fever (Gratz 2004). Notable studies of mosquito invasion biology have dealt with ecological and human-health impacts associated with range expansions in Aedes (Juliano and Lounibos 2005), novel routes of movement, and invasion pathways (Benedict et al. 2007). This work has shown that human travel and commercial trade routes and traffic create high risks of establishment for invasive disease vectors including Aedes spp. (Tatem et al. 2006; Kilpatrick 2011) with likely applicability to the recent Zika virus outbreaks (Hayes 2009). Another research area in which disease vectors have contributed substantial innovations in invasion science is in unlocking novel methods for controlling populations. For example, the classic study by Walker et al. (2011) showed how endosymbiontic bacterial Wolbachia infections can be used to control populations of invasive mosquitoes. Infection of the wMelPop-CA Wolbachia strain reduces longevity of A. aegypti mosquitoes and suppresses transmission of a dengue serotype, thereby offering a novel method for managing both the disease and the vector. There is also much interest in understanding disease dynamics, vector control, and potential climate change interactions (e.g. Caminade et al. 2014).

\section{Ecological impacts}

When considering the ecological impacts of invasive insects on biodiversity, ants have been ranked among the most influential taxa, as they have many direct and indirect effects on native communities and ecosystems (Lach and Hooper-Bui 2010). Ants provide excellent opportunities to study the ecological effects of insect invasions, especially in island ecosystems where natural enemies are often scarce or absent. The high diversity and abundance of ants favour complex species interactions and invasive ants often disrupt 
key insect-plant mutualisms, affect native seed dispersers, change native pollination services and interact with biological control programmes, ultimately affecting multiple ecosystem processes and often resulting in negative economic consequences due to reduced crop production and increased management costs. The relative ease of monitoring ants (Agosti et al. 2000) has facilitated the use of ecological data of invasive and recipient communities in comparative and modelling exercises, such as those predicting future distributions and impacts of invasive ants under climate change (see Bertelsmeier et al. 2016). Although there are many invasive ant species worldwide, most research on ant invasions has focused on two species, the Argentine ant, Linepithema humile and the fire ant, Solenopsis invicta (Kenis et al. 2009), although several other taxa are beginning to receive attention (Sanders and Suarez 2011). One characteristic that is shared among invasive ant species is the tendency to be unicolonial which enhances cooperation among individuals from separate nests and leads to the formation of supercolonies, resulting in low genetic diversity (Tsutsui and Suarez 2003). In contrast to theoretical expectations, such low genetic diversity provides an advantage to spread and survival of alien ants, at least in the short-term. Genetic and genomic tools have provided valuable information in uncovering unique mechanisms in the best-studied species (Suarez and Tsutsui 2008; Ascunce et al. 2011). Only two out of 19 invasive ant species listed by the Invasive Species Specialist Group (ISSG) have had their complete genomes sequenced (Smith et al. 2011; Wurm et al. 2011). As state-of-the-art technologies become more accessible, insights into the mechanisms and processes underlying ant invasions will become more realizable across species and regions.

\section{Biological control}

Many of the best studied insect invasions have resulted from intentional introductions of carefully selected species. There have been many successful examples of insect species that were introduced to a region for pest suppression of insects or plants (Hajek et al. 2016). The wide use of biological control agents has also shed much light on the key role of propagule pressure and establishment probability for launching invasions (see Simberloff 2009). Given the broad range of candidate species for biological control programmes, there are lessons to be learned regarding traits that promote invasiveness from case studies in this field. Some species introduced during the early years of biological control, went on to have non-target effects that resulted in widespread ecological impacts (Louda et al. 2003). The non-target effects of biological control can threaten local diversity, through competition, predation and host switching. One of the most notorious examples of non-target effects by an introduced insect natural enemy is the tachinid fly, Compsilura concinnata. This species was repeatedly introduced to control a number of pests, the main target being the gypsy moth in North America between 1906 and 1986 (Boettner et al. 2000). Due to the multivoltine nature of $C$. concinnata it requires secondary hosts when the univoltine target species are not available, and has thus parasitised a wide range of hymenopteran and lepidopteran hosts (Boettner et al. 2000; Louda et al. 2003). In particular the silk moths (Saturniidae) provide highly suitable hosts, and C. concinnata has greatly affected population dynamics across these species (Boettner et al. 2000). Such examples of non-target effects make some conservationists wary of possible unforeseen negative impacts in other systems (Louda et al. 2003; Hajek et al. 2016), although the number of instances where population level impacts of parasitoids and predators released for control of insects is very low. Today, strict controls on agent release, and outright bans on generalist agents, have increasingly strived to reduce the non-target effects of biological control agents (Hajek et al. 2016).

\section{The drivers, mechanisms, impacts and adaptation in insect invasions}

Increases in the numbers, frequency and impacts of insect invasions have highlighted the importance of achieving an improved understanding of these invasions. Both geographic and taxonomic biases need to be addressed so that emerging invasive species issues can be dealt with more systematically. This is especially important in the face of climate change and other anthropogenic influences which are set to modify the distributions and severity of insect invasions. Beyond the utilitarian benefits, there is a wealth of information to be gathered from investigating invasive insects to improve our overall understanding of the processes that shape biological invasions. This 
issue of Biological Invasions contains a collection of papers from the workshop; these were selected to provide a cross-section of research focus areas, namely the drivers, mechanisms, impacts and adaptation in insect invasions.

\section{Drivers}

Drivers of insect invasions typically include the pathways that facilitate movement of individuals, and the levels of propagule pressure associated with these. By comparing native versus non-native assemblages of invasive insects, Liebhold et al. (2016) showed that drivers of global insect invasion are more strongly linked to pathways than to the life-histories of the species involved. Roques et al. (2016) examined the rates of spread of invasive insects in Europe and explored how changes associated with political developments in Europe have influenced spread rates. Hurley et al. (2016) outlined how the worldwide planting of Eucalyptus species has been a major driver of insect invasions; they provide disturbing new insights on the pathways of these invasions. Garnas et al. (2016) and Roques et al. (2016) provide new evidence to show that invasive insect species are spreading much faster now than in the past-likely due to rapid changes to pathways (Garnas et al. 2016; Hurley et al. 2016; Roques et al. 2016). Although most invasive insects arrive accidentally as hitch-hikers or contaminants of commodities, in particular plants or plant products, biological control can also be a driver of insect invasions. Biological control using insects has been part of insect pest and weed management strategies for over a century, and when used appropriately, can provide an effective and environmentally responsible solution for control of invasive arthropods and plants (Hajek et al. 2016).

\section{Mechanisms}

Papers in the special issue considered functional traits and life-histories as well as novel interactions and dispersal strategies. Two papers take different approaches on how to define invasiveness and invasibility. Hui et al. (2016) adopt an ecological network approach in attempting to capture the complexity of recipient ecosystems for insect invaders. Duncan (2016) makes inferences from success rates of dung beetle introductions into Australia along climatic gradients. To highlight how model species can be used to understand invasions, Roy et al. (2016) demonstrate the power of global collaboration and have compiled an impressive dataset for Harmonia axyridis that highlights the variation in traits and the success of this global invader. Wingfield et al. (2016) examine novel interactions between native and nonnative insects and micoorganismal associates, and detail how these mechanisms of invasion can contribute to forest pestilence.

Impacts

The impacts of invasive insects are often regarded either as direct losses to biodiversity, or the economic implications of control. Impacts may also be measured in terms of the spread of disease and human mortality, and the social and economic costs of management and eradication of such vectors. Whilst these direct impacts are still at the core of invasion science, a recent paper by McGeoch et al. (2015) proposed that current impact assessments (e.g. for Aichi Target 9) overlook indirect impacts of insects, for example effects on food-webs and higher community impacts. Several contributions in this special issue deal with different types of impacts of invasive species. For example, Saccaggi et al. (2016) outline the procedures for detection, identification and response to invasive insects, and the constraints and challenges that face them. Kumschick et al. (2016) present an analysis of risk assessments for management of invasive species and recommendations on priorities for research and regulation. The ecological impacts that an invasive insect species may have on the system it invades are also investigated through the application of network approaches (e.g. Hui et al. 2016).

\section{Adaptation}

Adaptation lies at the core of biology and ecology, yet its role in invasions is remarkably poorly understood. Advances in this area are fundamental to deriving strong generalities in insect invasion biology. Evolutionary shifts that facilitate trait changes and promote enhanced invasibility of the organism are one form of adaptation that affects the outcome of a potential invasion. Adaptation to novel environmental conditions is also critical to insect range expansions and population persistence in suboptimal environmental 
conditions. To address this, Gibert et al. (2016) examined Drosophila species as model organisms for understanding rapid evolutionary adaptation during insect invasions. To better understand how invasive species may be influenced in future, and whether any common responses could occur, Hill et al. (2016) report on how climate change may shape future invasions of tephritid fruit flies. They show that general patterns of geographic distribution responses hide species-specific complexity. Such patterns are likely to challenge management and will require adaptation in strategies now and into the future.

\section{Conclusions}

The thirteen contributions in this special issue span the four main themes of the workshop. They draw on data from most parts of the world and illustrate how global collaborations can contribute to advancing the understanding of invasion science. The themes of the workshop are broad and not mutually exclusive in many instances, and many of the papers contribute insights beyond the themes to which they were intially assigned. We hope that this special issue provides a useful primer on key issues in insect invasion ecology and that the contributions will stimulate further research that is urgently needed to fill in the many gaps that exist in our understanding, thereby improving our ability to manage invasive insects.

\begin{abstract}
Acknowledgments The November 2014 workshop on "Drivers, impacts, mechanisms and adaptation in insect invasions" was hosted and co-funded by the DST-NRF Centre of Excellence for Invasion Biology at Stellenbosch University, South Africa. Additional financial support was provided by HortGro, the National Research Foundation of South Africa, Stellenbosch University, and SubTrop. We thank all the delegates for their participation and stimulating insights. DMR acknowledges funding from the National Research Foundation of South Africa (Grant 85417). We thank Laura Meyerson and Dan Simberloff for their support and advice during the preparation of this special issue. Andrew Liebhold, Marc Kenis and Ann Hajek all provided valuable comments on earlier drafts of this editorial.
\end{abstract}

\section{References}

Agosti D, Majer JD, Alonso L, Schultz TR (eds) (2000) Ants: standard methods for measuring and monitoring biological diversity. Smithsonian Institution Press, Washington
Ascunce MS, Yang C-C, Oakey J, Calcaterra L, Wu W-J, Shih C-J, Goudet J, Ross KG, Shoemaker D (2011) Global invasion history of the fire ant Solenopsis invicta. Science 331:1066-1068

Benedict MQ, Levine RS, Hawley WA, Lounibos LP (2007) Spread of the tiger: global risk of invasion by the mosquito Aedes albopictus. Vector-Borne Zoonotic 7:76-85

Bertelsmeier C, Blight O, Courchamp F (2016) Invasions of ants (Hymenoptera: Formicidae) in light of global climate change. Myrmecol News 22:25-42

Boettner GH, Elkinton JS, Boettner CJ (2000) Effects of a biological control introduction on three nontarget native species of saturniid moths. Conserv Biol 14:1798-1806

Boykin LM, Armstrong KF, Kubatko L, De Barro P (2012) Species delimitation and global biosecurity. Evol Bioinform 8:1-37

Caminade C, Kovats S, Rocklov J, Tompkins AM, Morse AP, Colón-González FJ, Stenlund H, Martens P, Lloyd SJ (2014) Impact of climate change on global malaria distribution. P Natl Acad Sci USA 111:3286-3291

Catford JA, Jansson R, Nilsson C (2009) Reducing redundancy in invasion ecology by integrating hypotheses into a single theoretical framework. Divers Distrib 15:22-40

Cook WC (1929) A bioclimatic zonation for studying the economic distribution of injurious insects. Ecology 10:282-293

Cook WC (1931) Notes on predicting the probable future distribution of introduced insects. Ecology 12:245-247

Davidson CB, Gottschalk KW, Johnson JE (1999) Tree mortality following defoliation by the European gypsy moth (Lymantria dispar L.) in the United States: a review. Forest Sci 45:74-84

De Barro PJ, Liu S, Boykin LM, Dinsdale AB (2011) Bemisia tabaci: a statement of species status. Annu Rev Entomol 56:1-19

De Meyer M, Robertson MP, Peterson AT, Mansell MW (2008) Ecological niches and potential geographical distributions of Mediterranean fruit fly (Ceratitis capitata) and Natal fruit fly (Ceratitis rosa). J Biogeogr 35:270-281

Duncan RP (2016) How propagule size and environmental suitability jointly determine establishment success: a test using dung beetle introductions. Biol Invasions. doi:10. 1007/s10530-016-1083-8

Elton CS (1958) The ecology of invasions by animals and plants. Methuen, London

Garnas J, Auger-Rozenberg, M-A, Roques A, Bertelsmeier C, Wingfield MJ, Saccaggi DL, Roy HE, Slippers B (2016) Complex patterns of global spread in invasive insects: ecoevolutionary and management consequences. Biol Invasions. doi:10.1007/s10530-016-1082-9

Gibert P, Hill MP, Pascual M, Plantamp C, Terblanche JS, Yassin A, Sgrò CM (2016) Drosophila as models to understand the adaptive process during invasion. Biol Invasions. doi:10.1007/s10530-016-1087-4

Gjullin CM (1931) Probable distribution of the Mediterranean fruit fly (Ceratitis capitata Weid.) in the United States. Ecology 12:248-258

Gratz NG (2004) Critical review of the vector status of Aedes albopictus. Med Vet Entomol 18:215-227

Gutierrez AP, Ponti L (2011) Assessing the invasive potential of the Mediterranean fruit fly in California and Italy. Biol Invasions 13:2661-2676 
Hajek AE, Hurley BP, Kenis M, Garnas JR, Bush SJ, Wingfield MJ, van Lenteren JC, Cock MJW (2016) Exotic biological control agents: a solution or contribution to arthropod invasions. Biol Invasions. doi:10.1007/s10530-016-1075-8

Hayes EB (2009) Zika virus outside Africa. Emerg Infect Dis 15:1347-1350

Herms DA, McCullough DG (2014) Emerald ash borer invasion of North America: history, biology, ecology, impacts, and management. Annu Rev Entomol 59:13-30

Hill MP, Bertelsmeier C, Clusella-Trullas S, Garnas JR, Robertson MP, Terblanche, JS (2016) Predicted decrease in global climate suitability masks regional complexity of invasive fruit fly species response to climate change. Biol Invasions. doi:10.1007/s10530-016-1078-5

Huang D, Haack RA, Zhang R (2011) Does global warming increase establishment rates of invasive alien species? A centurial time series analysis. PLoS One 6:e24733

Hui C, Richardson DM, Landi P, Minoarivelo HO, Garnas JG, Roy HE (2016) Defining invasiveness and invasibility in ecological networks. Biol Invasions. doi:10.1007/s10530016-1076-7

Hurley BP, Garnas JR, Wingfield MJ, Branco M, Richardson DM, Slippers B (2016) Increasing numbers and intercontinental spread of invasive insects on eucalypts. Biol Invasions. doi:10.1007/s10530-016-1081-x

Johnson DM, Liebhold AM, Bjørnstad ON (2006) Geographical variation in the periodicity of gypsy moth outbreaks. Ecography 29:367-374

Juliano SA, Lounibos LP (2005) Ecology of invasive mosquitoes: effects on resident species and human health. Ecol Lett 8:558-574

Kenis M, Rabitsch W, Auger-Rozenberg M-A, Roques A (2007) How can alien species inventories and interception data help us prevent insect invasions? Bull Entomol Res 97:489-502

Kenis M, Auger-Rozenberg MA, Roques A, Timms L, Péré C, Cock MJ, Settele J, Augustin S, Lopez-Vaamonde C (2009) Ecological effects of invasive alien insects. Biol Invasions 11:21-45

Kilpatrick AM (2011) Globalization, land use, and the invasion of West Nile virus. Science 334:323-327

Kumschick S, Devenish A, Kenis M, Rabitsch W, Richardson DR, Wilson JRU (2016) Intentionally introduced terrestrial invertebrates: patterns, risks, and options for management. Biol Invasions. doi:10.1007/s10530-016-1086-5

Lach L, Hooper-Bui LM (2010) Consequences of ant invasions. In: Lach L, Parr CL, Abbott KL (eds) Ant ecology. Oxford University Press, Oxford, pp 261-286

Liebhold AM, Tobin PC (2006) Growth of newly established alien populations: comparison of North American gypsy moth colonies with invasion theory. Popul Ecol 48:253-262

Liebhold AM, Work TT, McCullough DG, Cavey JF (2006) Airline baggage as a pathway for alien insect species invading the United States. Am Entomol 52:48-54

Liebhold AM, Yamanaka T, Roques A, Augustin S, Chown SL, Brockerhoff EG, Pyšek P (2016) Global compositional variation among native and non-native regional insect assemblages emphasizes the importance of pathways. Biol Invasions. doi:10.1007/s10530-016-1079-4

Louda SM, Pemberton RW, Johnson MT, Follett P (2003) Nontarget effects-the Achilles' heel of biological control? Retrospective analyses to reduce risk associated with biocontrol introductions. Annu Rev Entomol 48:365-396

Lowe S, Browne M, Boudjelas S, De Poorter M (2004) 100 of the world's worst invasive alien species. a selection from the global invasive species database. Published by The Invasive Species Specialist Group (ISSG) a specialist group of the Species Survival Commission (SSC) of the World Conservation Union (IUCN)

McGeoch MA, Lythe MJ, Henriksen MV, McGrannachan CM (2015) Environmental impact classification for alien insects: a review of mechanisms and their biodiversity outcomes. Curr Opin Insect Sci 12:46-53

Orwig DW, Thompson JR, Povak NA, Manner M, Niebyl D, Foster DR (2012) A foundation tree at the precipice: Tsuga canadensis health after the arrival of Adelges tsugae in central New England. Ecosphere 3:1-16

Pauly PJ (2002) Fighting the Hessian Fly: American and British responses to insect invasion; 1776-1789. Environ Hist 7:485-507

Pyšek P, Richardson DM, Jarošík V (2006) Who cites who in the invasion zoo: insights from an analysis of the most highly cited papers in invasion ecology. Preslia 78:437-468

Pyšek P, Richardson DM, Pergl J et al (2008) Geographical and taxonomic biases in invasion ecology. Trends Ecol Evol 23:237-244

Richardson DM (ed) (2011a) Fifty years of invasion ecology. The legacy of Charles Elton. Wiley, Oxford

Richardson DM (2011b) Invasion science: the roads travelled and the roads ahead. In: Richardson DM (ed) Fifty years of invasion ecology. The legacy of Charles Elton. Wiley, Oxford, pp 397-407

Roderick GR, Navajas M (2015) Invasions of terrestrial arthropods: mechanisms, pathways, and dynamics. In: Canning-Clode João (ed) Biological invasions in changing ecosystems vectors, ecological impacts, management and predictions. De Gruyter Open Ltd, Warsaw, pp 75-87

Roll U, Dayan T, Simberloff D (2007) Non-indigenous insect species in Israel and adjacent areas. Biol Invasions 9:629-643

Roques A, Auger-Rozenberg M-A, Blackburn TM, Garnas J, Pyšek P, Rabitsch W, Richardson DM, Wingfield MJ, Liebhold AM, Duncan RP (2016) Temporal and interspecific variation in rates of spread for insect species invading Europe during the last 200 years. Biol Invasions. doi:10.1007/s10530-016-1080-y

Roy HE, Brown PMJ, Adriaens T et al (2016) The harlequin ladybird, Harmonia axyridis: global perspectives on invasion history and ecology. Biol Invasions. doi:10.1007/ s10530-016-1077-6

Saccaggi DL, Karsten M, Robertson MP, Kumschick S, Somers MJ, Wilson JRU, Terblanche JS (2016) Methods and approaches for the management of arthropod border incursions. Biol Invasions. doi:10.1007/s 10530-016-1085-6

Sanders NJ, Suarez AW (2011) Elton's insights into the ecology of ant invasions: lessons learned and lessons still to be learned. In: Richardson DM (ed) Fifty years of invasion ecology. The legacy of Charles Elton. Wiley, Oxford

Sharov AA, Leonard D, Liebhold AM, Roberts EA, Dickerson W (2002) "Slow the Spread": a national program to contain the gypsy moth. J For 100:30-35 
Simberloff D (2009) The role of propagule pressure in biological invasions. Annu Rev Ecol Evol Syst 40:81-102

Smith CD, Zimin A, Holt C et al (2011) Draft genome of the globally widespread and invasive Argentine ant (Linepithema humile). P Natl Acad Sci USA 108:5673-5678

Suarez AV, Tsutsui ND (2008) The evolutionary consequences of biological invasions. Mol Ecol 17:351-360

Suckling DM, Stringer LD, Stephens AE, Woods B, Williams DG et al (2014) From integrated pest management to integrated pest eradication: technologies and future needs. Pest Manag Sci 70:179-189

Sutherst RW (2014) Pest species distribution modelling: origins and lessons from history. Biol Invasions 16:239-256

Suttle KB, Hoddle MS (2006) Engineering enemy-free space: an invasive pest that kills its predators. Biol Invasions 8:639-649

Tatem AJ, Hay SI, Rogers DJ (2006) Global traffic and disease vector dispersal. Proc Natl Acad Sci USA 103:6242-6247

Tobin PC, Berec L, Liebhold AM (2011) Exploiting Allee effects for managing biological invasions. Ecol Lett 14:615-624
Tsutsui ND, Suarez AV (2003) The colony structure and population biology of invasive ants. Conserv Biol 17:48-58

Vera MT, Rodriguez R, Segura DF, Cladera JL, Sutherst RW (2002) Potential geographical distribution of the Mediterranean fruit fly, Ceratitis capitata (Diptera: Tephritidae), with emphasis on Argentina and Australia. Environ Entomol 31:1009-1022

Walker T, Johnson PH, Moreira LA et al (2011) The wMel Wolbachia strain blocks dengue and invades caged Aedes aegypti populations. Nature 476:450-453

Wingfield MJ, Garnas JR, Hajek A, Hurley BP, de Beer ZW, Taerum SJ (2016) Novel and co-evolved associations between insects and microorganisms as drivers of forest pestilence. Biol Invasions. doi:10.1007/s10530-016-1084-7

Wurm Y, Wang J, Riba-Grognuz O et al (2011) The genome of the fire ant Solenopsis invicta. P Natl Acad Sci USA 108:5679-5684 